\title{
The impact of greenery on physical activity and mental health of adolescent and adult residents of deprived neighborhoods: A longitudinal study
}

Citation for published version (APA):

Gubbels, J. S., Kremers, S. P. J., Droomers, M., Hoefnagels, C., Stronks, K., Hosman, C., \& de Vries, S. (2016). The impact of greenery on physical activity and mental health of adolescent and adult residents of deprived neighborhoods: A longitudinal study. Health \& Place, 40, 153-160.

https://doi.org/10.1016/j.healthplace.2016.06.002

Document status and date:

Published: 01/07/2016

DOI:

10.1016/j.healthplace.2016.06.002

Document Version:

Publisher's PDF, also known as Version of record

Document license:

Taverne

Please check the document version of this publication:

- A submitted manuscript is the version of the article upon submission and before peer-review. There can be important differences between the submitted version and the official published version of record.

People interested in the research are advised to contact the author for the final version of the publication, or visit the DOI to the publisher's website.

- The final author version and the galley proof are versions of the publication after peer review.

- The final published version features the final layout of the paper including the volume, issue and page numbers.

Link to publication

\footnotetext{
General rights rights.

- You may freely distribute the URL identifying the publication in the public portal. please follow below link for the End User Agreement:

www.umlib.nl/taverne-license

Take down policy

If you believe that this document breaches copyright please contact us at:

repository@maastrichtuniversity.nl

providing details and we will investigate your claim.
}

Copyright and moral rights for the publications made accessible in the public portal are retained by the authors and/or other copyright owners and it is a condition of accessing publications that users recognise and abide by the legal requirements associated with these

- Users may download and print one copy of any publication from the public portal for the purpose of private study or research.

- You may not further distribute the material or use it for any profit-making activity or commercial gain

If the publication is distributed under the terms of Article $25 \mathrm{fa}$ of the Dutch Copyright Act, indicated by the "Taverne" license above, 


\title{
The impact of greenery on physical activity and mental health of adolescent and adult residents of deprived neighborhoods: A longitudinal study
}

\author{
Jessica S. Gubbels ${ }^{\mathrm{a}, *}$, Stef P.J. Kremers ${ }^{\mathrm{a}}$, Mariël Droomers ${ }^{\mathrm{b}}$, Cees Hoefnagels ${ }^{\mathrm{c}}$, \\ Karien Stronks ${ }^{\mathrm{b}}$, Clemens Hosman ${ }^{\mathrm{a}, \mathrm{d}}$, Sjerp de Vries ${ }^{\mathrm{e}}$ \\ ${ }^{\text {a }}$ Maastricht University, NUTRIM School of Nutrition and Translational Research in Metabolism, Dep. of Health Promotion, PO Box 616, 6200 MD Maastricht, \\ The Netherlands \\ ${ }^{\mathrm{b}}$ University of Amsterdam, Dep. of Public Health, PO Box 22660, 1100 DD Amsterdam, The Netherlands \\ ${ }^{\mathrm{c}}$ Trimbos Institute, Centre Youth, PO Box 725, 3500 AS, The Netherlands \\ d Radboud University, Department of Clinical Psychology, PO Box 9104, 6500 HE Nijmegen, The Netherlands \\ ' Wageningen UR, Alterra/Cultural Geography, PO Box 47, 6700 AA Wageningen, The Netherlands
}

\section{A R T I C L E I N F O}

\section{Article history:}

Received 25 January 2016

Received in revised form

2 June 2016

Accepted 7 June 2016

Available online 17 June 2016

Keywords:

Greenery

Deprived neighborhood

Physical activity

Depressive symptoms

\begin{abstract}
A B S T R A C T
The aim of the study is to assess the impact of perceived and objective changes in greenery on physical activity and mental health of adolescents and adults living in severely deprived neighborhoods in the Netherlands.

Longitudinal data regarding changes in greenery, walking, cycling, and depressive symptoms (CES-D), were gathered for 401 adolescents and 454 adults, using questionnaires and interviews with local district managers. Multivariate linear regression models examined the association between greenery and outcome variables, correcting for demographic and socioeconomic covariates and season.

Overall, the results showed small and non-significant associations, with two exceptions. Objective improvements in greenery were associated with smaller decline in adolescents' leisure time cycling, and improvements in perceived greenery were related to a decrease in adults' depressive symptoms. In addition, there were several subgroup effects.

In conclusion, changes in greenery did not yield consistent positive results among residents of severely deprived neighborhoods. However, there are some indications regarding positive effects of greenery in certain subgroups.
\end{abstract}

(c) 2016 Elsevier Ltd. All rights reserved.

\section{Introduction}

Greenery or natural elements in living neighborhoods offer opportunities for mental restoration and can consequently positively affect mental health (e.g., De Vries et al., 2013; Hartig et al., 2014; Lee and Maheswaran, 2010; Van den Berg et al., 2016). In addition, greenery can provide opportunities for physical activity (e.g., Hunter et al., 2015; Lee and Maheswaran, 2010; Mytton et al., 2012; Sallis et al., 2016). However, the evidence to date seems largely inconsistent (e.g., De Vries, et al., 2013; Hartig, et al., 2014; Koohsari et al., 2015; Lee and Maheswaran, 2010).

Socio-ecological frameworks hypothesizing the impact of the environment on health and health behavior (Kremers et al., 2006;

\footnotetext{
* Corresponding author.

E-mail addresses: Jessica.gubbels@maastrichtuniversity.nl (J.S. Gubbels), s.kremers@maastrichtuniversity.nl (S.P.J. Kremers).
}

Sallis et al., 2006) have inspired studies which gave inconclusive insights (Ferdinand et al., 2012; Van Cauwenberg et al., 2011). One of the main causes for inconsistency in study results reflects the study design that is typically applied in such studies. Cross-sectional studies are unable to address issues related to selective mobility, and longitudinal studies often suffer from a lack of change in predictor variables. An excellent recent study by Sallis et al. (2016) in a very large sample of adults from 14 cities worldwide, using objective measures of both the physical environment and physical activity, showed a significant, positive association between the number of parks in a neighborhood, and residents' physical activity. This study was, however, cross-sectional (Sallis et al., 2016). The strongest evidence likely comes from studies with a (quasi-)experimental approach in which green spaces are created or improved. The number of this type of studies is relatively limited, with mixed results: some show positive effects, while others report no effect of greenery improvements on health or health behavior (Branas et al., 2011; Cohen et al., 2009; 
Droomers et al., 2015; Fitzhugh et al., 2010; Hunter et al., 2015; Tester and Baker, 2009). Subgroup differences regarding the impact of greenery on health and behavior could perhaps also partially explain these mixed results (Hartig et al., 2014).

Regarding the impact of environmental features on behavior and health, a distinction needs to be made between objective and perceived measures of the environment. Subjectively perceived environments may not match those that are assessed objectively, but they may be better predictors of self-reported health behavior. Objectively assessed environmental features may be better correlates of health outcomes, since they may also take unconscious, or unmediated, environment-behavior processes into account (Tilt et al., 2007), and they are more useful for spatial planning. The agreement between objectively measured (e.g. through street audits or Geographic Information Systems) aspects of physical environments and perceptions of these environments (as measured with interviews or questionnaires) is generally moderate or low (Kweon et al., 2006; Leslie et al., 2010), therefore they may both in themselves be important in explaining and predicting physical activity (Boehmer et al., 2007). Furthermore, perceived environmental improvements might mediate part of the association between objective improvements and health. In addition to the issue of subjectively versus objectively measured environments, there are other conceptual and measurement issues which influence findings in this research area. These include the reliance of many studies self-report of outcomes, variability in definitions of greenery and public open space, the lack of assessment of the actual location of behavior (e.g. whether physical activity is actually performed in green spaces), the lack of measurement of quality of the green spaces, and many other issues (Koohsari et al., 2015).

This paper reports on a longitudinal assessment of the impact of changes in residential greenery in severely deprived neighborhoods in the Netherlands. The main aim of the present study is to assess the impact of changes in objective and subjective amount and quality of greenery on walking, cycling and mental health of adolescents and adults, within this specific and hard to reach research population. A secondary aim is to examine moderation of the association between greenery and mental health and physical activity, by residents' demographic characteristics, in order to study potential subgroup effects of greenery. Finally, we explore residents' perceptions of green spaces as a potential mediating pathway between changes in greenery and outcomes.

\section{Methods}

\subsection{Study population and design}

The current study deployed a longitudinal, observational design. Data originated from twenty severely deprived districts in the Netherlands. Ten districts were randomly selected from the URBAN40 longitudinal study on the physical and mental health effects of the Dutch District Approach, which targeted the 40 most severely deprived districts in the Netherlands. The District Approach was launched by the Dutch government in order to increase the livability in these neighborhoods. In 2009, the districts put their plans into action and have been implementing interventions since then. Until 2012, around 5 billion euros had been spent to ameliorate problems with employment, education, housing and the residential environment, social integration, and safety.

In addition to the 10 districts selected from the Urban 40 study, 10 districts were selected from a list with the 100 subsequently most deprived districts in The Netherlands, i.e. the numbers 41 until 140. Four municipal authorities refused to participate in this study. We invited 8 other randomly selected districts from municipalities on the list, to substitute those that refused. We included those 4 other districts that were the first to consent to participate in this study. All 20 participating districts were located in cities.

For each of the 20 participating districts, municipalities delivered a list of 250 randomly selected adolescents, aged between 12 and 15 years. Parents of these adolescents were sent an invitation by post for their child to participate, including a personal code for an internet questionnaire. In addition, 250 randomly selected adults in each of the 20 participating districts were sent an invitation to participate by post. Up to two reminders were sent when they did not respond. In addition, trained interviewers from two interview agencies, of which one specialized in research in multicultural populations, recruited non-respondent participants by home visits to personally invite the respondents to answer questions. The questionnaire took about $30-45 \mathrm{~min}$ to fill in. Parents of adolescents were asked for their approval of the adolescents' participation. Participants received a gift voucher of $€ 10$. Discharge was granted for approval by the Medical Research Involving Human Subjects Act (WMO) by an independent medicalethical review committee on January 21, 2010.

\subsection{Study sample}

A total of 994 adolescents (response rate: 19.9\%) participated in the first measurement wave (May 2010-May 2011). Of those, 401 (40.3\%) filled in the questionnaire for the second measurement between May and July 2012. Those who did not participate in the second measurement wave, significantly $(p<0.05)$ more often were boys, from a non-Dutch background and low educated. There were no differences regarding age or recruitment group.

A total of 727 adults (response rate: 14.5\%) filled in the first questionnaire between May 2010 and May 2011. Of those, 454 (62.4\%) filled in the questionnaire for the second measurement between May and July 2012. Those who did not participate in the second measurement wave, significantly $(p<0.05)$ more often were of Dutch origin and younger. There were no differences regarding sex, educational level, recruitment group and the socioeconomic status score of the residential area.

\subsection{Measurements}

\subsubsection{Greenery}

2.3.1.1. Perceived greenery. Perceived greenery was assessed in both measurements by the following items from The Neighborhood Walkability Scale (NEWS; Saelens et al., 2003): 'There are trees alongside the streets in my neighborhood', and 'There is much nice nature in my neighborhood (e.g. flower beds, gardens, nice views)'. The answers were given on a four point Likert scale ('Completely disagree' (1) to 'Totally agree' (4)). A higher score corresponded with more perceived greenery. We computed a change-score for both items to indicate changes in perceived greenery, with higher change scores indicating an increase in perceived greenery between the two measurement points.

2.3.1.2. Greenery interventions. In addition to the changes in perceived greenery, at the end of 2011 and in early 2012, we also retrospectively collected detailed objective information on the interventions that had been implemented (type, duration, scale) in the 10 districts that were part of the Dutch District Approach. We used standardized questionnaires and extensive face-to-face interviews with the local district managers that coordinated the District Approach in their own district. The questionnaire focused on 18 different types of activities, among which investments to improve green space in a specific district. For each district, we listed all activities implemented in this field of action for longer 
than 1 year (see Droomers et al. (2014) for more information). We distinguished between districts that improved their green character (e.g. by adding extra trees along roads) or the green space that can be used by residents (e.g. for recreation; 1 ) and those that did not (0). Note that the study sample that was available for addressing the research questions regarding the impact of greenery interventions (208 adolescents and 241 adults, from 10 target districts) was smaller than the available sample for the research questions related to perceived greenery (401 adolescents and 454 adults, from 20 districts).

\subsubsection{Physical activity}

Walking and cycling behavior were studied as physical activity behaviors that are most likely to be impacted by interventions in green space. For both behaviors, a distinction was made between active transport (going from A to B) and physical activity in leisure time (from A to A). The validated SQUASH questionnaire (Campbell et al., 2015; Wendel-Vos et al., 2003) measured physical activity by asking respondents to think about a regular week in the past month. Respondents then indicated how many days per week they engaged in several forms of physical activity and how many minutes they engaged in them. From this, total minutes of walking and cycling for active transport and leisure time walking and cycling per day were calculated. We computed a change-score for all behaviors, with higher scores indicating an increase in reported activities between the two measurement points.

\subsubsection{Depressive symptoms}

The Center for Epidemiologic Studies-Depression Scale (CES-D) is a validated self-report scale to measure depressive symptoms (Radloff, 1977). Participants were asked to report the frequency of 20 depressive symptoms experienced in the past week with the following answering categories: 'Not at all (less than one day)' (0), 'a little (1-2 days)' (1), 'some (3-4 days)' (2), and 'a lot (5-7 days)' (3). For each participant with at least 19 of the 20 CES-D items completed, we calculated a summative score between 0 and 60 . The higher the summative score, the more depressive symptoms were experienced. The total score had good internal reliability reflected by the Cronbach's alphas (Adults: 0.85 at the first and 0.90 at the second measurement; Adolescents: 0.79 at the first and 0.81 at the second measurement). We computed a change-score for CES-D, with positive change scores indicating an increase in depressive symptoms.

\subsubsection{Perceptions of greenery improvement and use}

In the second measurement, we added three questions to the questionnaire that specifically addressed the perceived improvement and use of greenery in the living environment, as these could possibly function as mediators between improvements in greenery and physical activity behavior and mental health. First we asked respondents to rate the following statement: 'The quality of the green space (such as woods, parks, natural areas) in my living environment has improved over the past years'. Answers were given on a five point Likert scale ('Completely disagree' (1) to 'Totally agree' (5)). A higher score corresponded with a more positive evaluation of the green spaces. In addition, we asked: 'In the past year, how often have you been physically active (i.e. walking, cycling, swimming or running) in the green space in your living environment?' And 'How often have you mentally come to rest in the green spaces in your living environment?' The answers were given on a five point scale ('Very seldom' (1) to 'Very often' (5)).

\subsubsection{Demographic and socioeconomic characteristics}

Age was calculated based on the date of birth and the date of completion of the questionnaire. Gender was assessed using a multiple-choice question. Ethnic background was based on the country of birth of the respondent as well as that of both parents. Respondents who were born abroad in a non-western country or with at least one parent who was born abroad on a non-western country, were classified as migrants. Educational level was based on the highest completed education, in line with ISCED levels (adults; UNESCO, 2011) or the current education (adolescents) at the second measurement point. For adolescents, we distinguished between education for children with special needs or primary education, lower secondary education, upper secondary education and children who currently do not go to school. For adults we distinguished between low (no education finished, Koran school, primary education, or lower secondary education finished), medium (higher secondary education, or short-cycle tertiary education finished) and high educational level (Bachelor's or Master's level).

\section{Statistical analyses}

Based on previous studies, we hypothesized that improvement in greenery would increase physical activity and decrease depressive complaints. In addition, we hypothesized that these associations would be moderated by demographic variables, creating differential subgroup effects. Finally, we hypothesized that the associations between changes in greenery and outcomes would be mediated by participants' perception of greenery improvements and use.

Participants who completed both measurements were included in the analyses. All analyses were conducted separately for the adolescent and adult samples. In all analyses, p-values $<0.05$ were considered statistically significant. Frequencies were used to provide information on the distribution of background variables in the sample and descriptive analyses (means and standard deviations) were run for all variables in the model. Paired sample $t$-tests were performed to examine whether there were significant differences between the first and second measurement in the independent and dependent variables.

Bivariate correlations were used to examine the correlations between changes in perceived green spaces and green space interventions on the one hand, and physical activity and depressive symptoms on the other hand.

Based on likelihood ratio tests within multi-level linear regression analyses, we concluded that there was no significant effect of the nesting of respondents within neighborhoods on the analyses $(P>0.05)$. Therefore, hierarchical multivariate linear regression models were run to assess the predictive value of the variables related to greenery with respect to the outcome variables (walking, cycling, depressive symptoms). These regression models were corrected for potential confounding effects of demographic and socioeconomic covariates (gender, age, ethnicity and educational level), as well as for the season of measurement. Separate analyses were conducted examining improvements of subjective greenery (within the whole sample, 20 districts) and greenery interventions (within the 10 districts in the District Approach).

In order to examine a potential intermediate pathway between greenery and health outcomes, potential mediators as described above (perceptions of improvement of greenery, and perceptions of coming to rest and being active in green spaces) were examined. These intermediate pathways were only examined in case of a significant association between greenery and outcome variables, based on the linear regression analyses described above. The methods of Baron and Kenny (MacKinnon et al., 2007) were used to explore potential mediation. These mediation analyses were corrected for all demographic and socioeconomic covariates as well as for the season of measurement.

Finally, interaction terms between the greenery variables on the one side and all the personal background variables of the 
sample on the other side, were added to the regression analyses, in order to examine possible moderation of the influence of greenery by demographic characteristics (gender, age, ethnicity and educational level). Interactions were deleted from the model starting with the least significant one, until only significant interaction terms were left (backward procedure). Stratified regression analyses were performed for all demographic characteristics involved in significant interactions. For these stratified analyses, age was divided into two groups using a median split (for adults and adolescents separately).

\section{Results}

Table 1 shows the background characteristics of the respondents. In both samples (adolescents and adults) there were slightly more females than males. The majority of the respondents were of Dutch origin, and they most often had a low educational level.

Table 2 shows changes in the independent and dependent variables between both measurements. Most variables show only small, non-significant changes, with a few exceptions. In adolescents, leisure time walking decreased significantly by 89.2 min per week on average and leisure time cycling decreased significantly by $62.7 \mathrm{~min}$ per week on average. Depressive symptoms increased significantly in adolescents. Furthermore, both adolescents and adults perceived significantly less nature in their neighborhood at the second measurement.

4.1. Association between greenery and physical activity and mental health

In the whole sample (20 districts), changes in perceived greenery in the neighborhood (i.e. trees and nature) were not significantly related to changes in any of the physical activity variables (see Table 3). There was a significant negative relationship between changes in the number of trees in the neighborhood and changes in depressive symptoms in adults (CES-D; $\beta=-0.12$, $\mathrm{p}<0.05$ ).

As regards the sample from the District Approach (10 districts), greenery interventions were significantly associated with more leisure time cycling in adolescents $(\beta=0.19, \mathrm{p}<0.05)$, but not with any other dependent variable in both adolescents and adults ( $p>0.05$; see Table 3). Adolescents who lived in neighborhoods in which greenery interventions were implemented, showed less decrease in their cycling in leisure time (decrease $5.6 \mathrm{~min} /$ day, on average) than adolescents who lived in neighborhoods without greenery improvements ( $14.6 \mathrm{~min} / \mathrm{day} ; \mathrm{p}<0.05$ ).

\subsection{Pathways between greenery and outcomes}

Pathways were examined for significant associations between changes in greenery and outcomes: the association between objectives changes in greenery and change in leisure time cycling in

Table 1

Descriptive characteristics of the sample at the second measurement.

\begin{tabular}{|c|c|c|c|c|c|c|}
\hline & & \multicolumn{2}{|c|}{ Adolescents $(\mathrm{N}=\mathbf{3 0 1})$} & & \multicolumn{2}{|c|}{ Adults $(\mathrm{N}=447)$} \\
\hline & & $\mathbf{N}(\%)$ & Mean (SD) & & $\mathbf{N}(\%)$ & Mean \\
\hline \multirow[t]{2}{*}{ Gender } & Male & $170(42.4 \%)$ & & & $198(44.3 \%)$ & \\
\hline & Female & $231(57.6 \%)$ & & & $249(55.7 \%)$ & \\
\hline Age (years) & & & $13.23(0.86)$ & & & $46.26(14.00)$ \\
\hline \multirow{2}{*}{ Ethnicity } & Dutch origin & $209(52.1 \%)$ & & & $305(69.0 \%)$ & \\
\hline & Migrant & 192 (47.9\%) & & & $137(31.0 \%)$ & \\
\hline \multirow[t]{5}{*}{ Educational level } & Primary education & $11(2.7 \%)$ & & Low & $192(44.4 \%)$ & \\
\hline & Lower secondary education & $166(41.4 \%)$ & & Medium & $123(28.5 \%)$ & \\
\hline & & & & High & 117 (27.1\%) & \\
\hline & Upper secondary education & $183(45.6 \%)$ & & & & \\
\hline & Other & $41(10.2 \%)$ & & & & \\
\hline
\end{tabular}

N's deviate from total sample size due to missing values. Percentages represent valid percentages.

Table 2

Means and standard deviations of independent and dependent variables: differences between first and second measurement

\begin{tabular}{|c|c|c|c|c|c|c|c|}
\hline & & \multicolumn{3}{|l|}{ Adolescents } & \multicolumn{3}{|l|}{ Adults } \\
\hline & & \multicolumn{3}{|l|}{ Mean (SD) } & \multicolumn{3}{|l|}{ Mean (SD) } \\
\hline & & First measurement & Second measurement & Change score $^{c}$ & First measurement & Second Measurement & Change score ${ }^{c}$ \\
\hline \multirow[t]{2}{*}{ Perceived greenery $^{\mathrm{a}}$} & Trees & $3.42(0.81)$ & $3.41(0.77)$ & $-0.01(.93)$ & $1.67(0.87)$ & $1.75(0.97)$ & $0.08(0.98)$ \\
\hline & Nature & $2.55(1.02)$ & $2.36(0.98)$ & $-0.20(1.09)^{* * *}$ & $2.23(0.93)$ & $2.12(0.89)$ & $-0.11(0.96)^{*}$ \\
\hline \multirow[t]{2}{*}{ Active transport (min/week) } & Walking & $20.0(62.5)$ & $16.9(47.7)$ & $-3.1(72.5)$ & $46.0(182.6)$ & $37.7(220.7)$ & $-8.3(230.6)$ \\
\hline & Cycling & $98.4(124.0)$ & $101.0(11.2)$ & $2.6(123.0)$ & $49.2(148.7)$ & $42.9(102.3)$ & $-6.3(137.9)$ \\
\hline \multirow[t]{2}{*}{ Leisure time PA (min/week) } & Walking & $368.0(529.9)$ & $278.8(397.3)$ & $-89.2(575.4)^{* *}$ & $240.4(282.4)$ & $242.1(333.7)$ & $1.73(360.5)$ \\
\hline & Cycling & $206.0(354.5)$ & $143.3(240.8)$ & $-62.7(378.8)^{* *}$ & $165.1(268.2)$ & $172.0(272.0)$ & $6.9(320.4)$ \\
\hline Depressive symptoms ${ }^{\mathrm{b}}$ & & $9.36(7.26)$ & $10.90(8.34)$ & $1.55(8.17)^{* * *}$ & $9.02(8.77)$ & $9.35(8.60)$ & $0.34(8.14)$ \\
\hline
\end{tabular}

$\mathrm{BMI}=$ body mass index, $\mathrm{PA}=$ physical activity, $\mathrm{SD}=$ standard deviation.

${ }^{*} \mathrm{p}<0.05$

*** $\mathrm{p}<0.01$.

${ }^{* * *} \mathrm{p}<0.001$.

a Derived from NEWS, scale 1 (totally disagree) to 4 (totally agree)

b Derived from CES-D, Scale 0-60.

c Significance levels from paired $t$-test between first and second measurement, unadjusted for potential confounders. 
Table 3

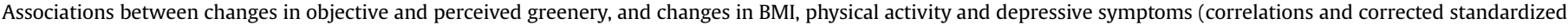
regression coefficients).

\begin{tabular}{|c|c|c|c|c|c|c|c|c|c|c|c|}
\hline & & \multicolumn{4}{|c|}{ Adolescents changes scores } & \multirow{3}{*}{$\begin{array}{l}\text { Depressive } \\
\text { symptoms }^{d}\end{array}$} & \multicolumn{4}{|c|}{ Adults changes scores } & \multirow{3}{*}{$\begin{array}{l}\text { Depressive } \\
\text { symptoms }^{\mathrm{d}}\end{array}$} \\
\hline & & \multicolumn{2}{|c|}{ Active transport } & \multicolumn{2}{|c|}{ Leisure time PA } & & \multicolumn{2}{|c|}{ Active transport } & \multicolumn{2}{|c|}{ Leisure time PA } & \\
\hline & & Walking & Cycling & Walking & Cycling & & Walking & Cycling & Walking & Cycling & \\
\hline \multirow{3}{*}{$\begin{array}{l}\text { CORRELATIONS } \\
\text { Changes in perceived } \\
\text { greenery }^{\mathrm{a}}\end{array}$} & & & & & & & & & & & \\
\hline & Trees & 0.03 & -0.08 & -0.05 & 0.07 & -0.03 & 0.05 & -0.02 & 0.07 & 0.11 & $-0.10 *$ \\
\hline & Nature & 0.02 & -0.05 & -0.06 & -0.02 & -0.01 & 0.04 & -0.02 & -0.03 & 0.00 & -0.02 \\
\hline Greenery interventions $^{\mathrm{b}}$ & & -0.02 & -0.11 & -0.09 & 0.10 & 0.05 & 0.04 & 0.00 & 0.02 & -0.08 & 0.16 \\
\hline STANDARDIZED BETAS ${ }^{\mathrm{c}}$ & & & & & & & & & & & \\
\hline $\begin{array}{l}\text { Changes in perceived } \\
\text { greenery }^{\mathrm{a}}\end{array}$ & Trees & 0.04 & -0.09 & -0.04 & 0.07 & -0.03 & 0.06 & 0.00 & 0.09 & 0.11 & -0.12 \\
\hline Greenery interventions $\mathrm{s}^{\mathrm{b}}$ & Nature & 0.04 & -0.04 & -0.04 & -0.03 & -0.02 & 0.05 & 0.01 & -0.04 & -0.02 & 0.01 \\
\hline Greenery interventions $^{\mathrm{b}}$ & & -0.02 & -0.01 & -0.05 & 0.19 & 0.05 & 0.11 & 0.08 & -0.03 & -0.03 & 0.10 \\
\hline
\end{tabular}

Significant associations are printed bold. $\mathrm{BMI}=$ body mass index, $\mathrm{PA}=$ physical activity. ${ }^{* * *} \mathrm{p}<0.01,{ }^{* * *} \mathrm{p}<0.001$.

${ }^{*} \mathrm{p}<0.05$.

a Derived from NEWS, scale 1 (totally disagree) to 4 (totally agree).

${ }^{\mathrm{b}}$ Only in intervention group.

c Standardized betas from regression analyses, corrected for season, age, sex, ethnicity and educational level.

${ }^{\mathrm{d}}$ Derived from CES-D, scale 0-60.

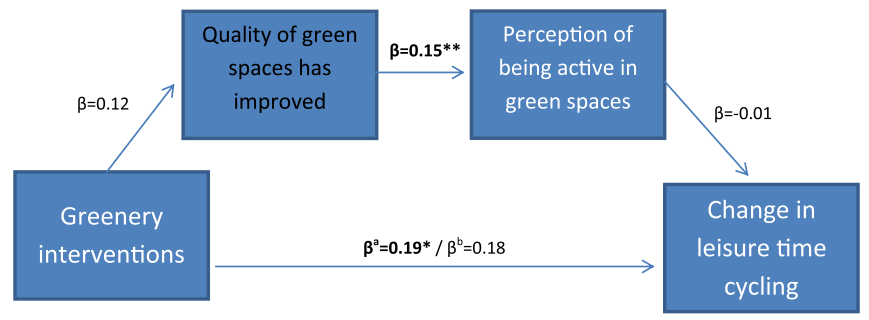

Fig. 1. Examination of intermediate pathway between the association between objective changes in greenery and adolescents' leisure time cycling (10 intervention districts only). Standardized betas, corrected for season, age, sex, ethnicity and educational level. Significant associations are printed bold. ${ }^{*} \mathrm{p}<0.05$, ${ }^{* *} \mathrm{p}<0.01$, ${ }^{* * *} \mathrm{p}<0.001$. ${ }^{a}$ Standardized $\beta$ not corrected for intermediate variables; 'Standardized $\beta$ corrected for intermediate variables.

adolescents $(\beta=0.19, \mathrm{p}<0.05)$, and the association between changes in number of street trees and changes in depressive symptoms in adults $(\beta=-0.12, \mathrm{p}<0.05)$. Fig. 1 shows that the association between change in greenery and change in leisure time cycling in adolescents is not mediated by perceptions of improved quality of green spaces and perceptions of being active in green spaces. The association changes only minimally by adding the potential mediators (although it becomes non-significant), and most of associations reflecting intermediate steps are non-significant $(\mathrm{p}>0.05)$. The only significant association was between the perceived improvement of quality of green spaces and the perception of being active in green spaces $(\beta=0.15, \mathrm{p}<0.01)$.

The association between the change in street trees and change in depressive symptoms in adults did seem to be mediated by respondents' perceptions (see Fig. 2). The change in number of street trees was positively associated with perceived improvements of the quality of green spaces $(\beta=0.18, p<0.001)$, which in turn was positively associated with respondents perception of coming to rest mentally in green spaces $(\beta=0.22, \mathrm{p}<0.001)$. Furthermore, this perception of coming to rest in green spaces was negatively associated with changes in depressive symptoms between both measurement moments $(\beta=-0.12, \mathrm{p}<0.05)$. Moreover, the association between changes in street trees and depressive symptoms became non-significant after addition of the mediators.

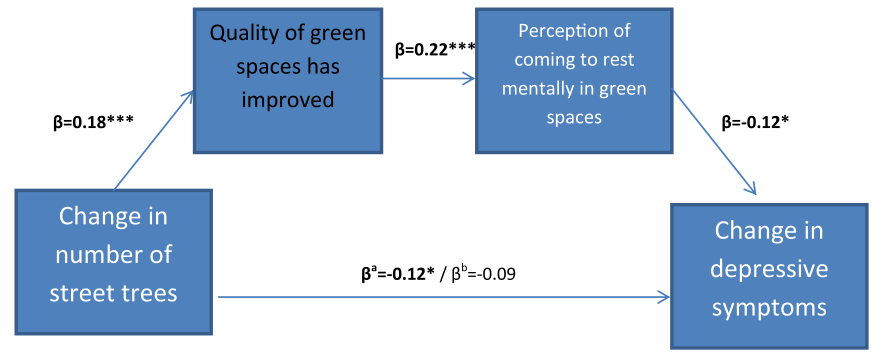

Fig. 2. Examination of intermediate pathway between the association between change in trees and change in adults' depressive symptoms (all 20 districts). Standardized betas, corrected for season, age, sex, ethnicity and educational level. Significant associations are printed bold. ${ }^{*} \mathrm{p}<0.05,{ }^{* *} \mathrm{p}<0.01,{ }^{* * *} \mathrm{p}<0.001$. ${ }^{\mathrm{a}} \mathrm{S}$ tandardized $\beta$ not corrected for intermediate variables; ${ }^{b}$ Standardized $\beta$ corrected for intermediate variables.

\subsection{Association between greenery and outcomes in subgroups}

Subgroup analyses (results not tabulated) based on significant interaction terms in the regression analyses showed that increases in the perception of the number of trees in the neighborhood were significantly associated with increased walking for active transportation in adolescents in the highest educational level $(\beta=0.35$, $p<0.01$ ), but not in other adolescents $(p>0.05)$. Increases in the perception of nature in the neighborhood were negatively associated with changes in leisure time walking in boys $(\beta=-0.17$, $\mathrm{p}<0.05$ ) but not girls $(\mathrm{p}>0.05)$.

In adults, there were several interactions between changes in the perception of greenery and age. In older adults ( $>$ median of 46 years), an increase in the perceived amount of nature in the neighborhood was associated with an increase in leisure time walking $(\beta=0.16, p<0.05)$. In younger adults ( $\leq 46$ years) this association was not present ( $\mathrm{p}>0.05)$. Furthermore, an increase in perceived nature was associated with increased walking for active transportation in adults from Dutch origin $(\beta=0.13, \mathrm{p}<0.05)$, but with decreased leisure time walking for migrant adults $(\beta=-0.25$, $\mathrm{p}<0.05$ ). 


\section{Discussion}

The present study aimed to gain insight into the impact of both perceived changes in greenery or natural elements in the neighborhood and greenery interventions, on walking, cycling and mental health of Dutch very low-SES adolescents and adults. Overall, the results showed small and non-significant associations between changes in greenery and changes in outcomes, with two major exceptions. Greenery interventions were associated with more leisure time cycling among adolescents, and improvements in perceived natural elements (i.e., more street trees) were related with a decrease in depressive symptoms among adults. As both for subjective (perceived changes in greenery) and objective (greenery interventions) measures the associations were mostly small and non-significant, we cannot conclude based on the current study which measure is more valuable. However, we did show that the negative association between changes in greenery and depressive symptoms in adults is partially mediated by perceptions of improvements and use of green spaces. Based on these findings, we feel that both objective and subjective measures should be included in studies regarding the impact of environments on behavior and health.

Our results regarding the association between changes in greenery and changes in walking and cycling were mixed, which is in line with most previous studies in this area (Lachowycz and Jones, 2011). In line with a study among younger Dutch adolescents (9-12 years; Van Kann et al., 2014), we found that greenery interventions were related to less decrease in adolescents' leisure time cycling. This may indicate that greenery interventions might be able to slow down the process of decreased physical activity throughout adolescence, which was found in the current study as well as various previous studies (Dumith et al., 2011). The fact that this association was not mediated by adolescents' perceptions of improvements of the quality of green spaces and their perceptions of use of green spaces for physical activity, might indicate that there was a direct, unconscious effect of greenery on their leisure time cycling. Such direct effects have been suggested before by Kremers et al. (2006). However, since leisure time cycling was the only outcome among adolescents (of six tested) that was significantly related to objective greenery interventions, these results need to be interpreted with caution. Based on a review of reviews, Hartig and colleagues have argued that especially for active transportation, other environmental factors such as distance to destination, safety and suitable infrastructure, might be more important than attractive natural features (Hartig et al., 2014). Alfonzo calls this the hierarchy of physical activity needs (Alfonzo, 2005). Also social environmental factors might play an important role. In a review of intervention studies to promote physical activity in green spaces, Hunter et al. (2015) showed that increasing greenery in the physical environment, combined with physical activity promoting programs, are most likely to have positive effects on physical activity (Hunter et al., 2015). This is line with the hypothesized synergistic effect of several environmental types, as hypothesized by ecological frameworks (see e.g. Gubbels et al. (2014)). In addition, the dose of greenery might also be important. An Australian study among children showed a ceiling effect of greenery in the neighborhood: there was little additional benefit of greenery after a modest amount was met (Sanders et al., 2015a). A similar effect might be in place for adults' physical activity and adolescents' active transport in the Netherlands. Furthermore, a recent study in the UK has shown that more than half of adults' physical activity takes place outside of their proximal neighborhood (800 m buffer; Hillsdon et al., 2015). Although the current study focused on activities that are most likely to occur within one's own neighborhood (i.e. walking and cycling), the proportion of physical activity outside the home neighborhood possibly explains part of the limited effect of neighborhood greenery on residents' physical activity.

The potential impact of improvements in greenery on mental health can be explained by assumptions from the Stress Reduction Theory (Ulrich et al., 1991) and the Attention Restoration Theory (Kaplan and Kaplan, 1989), which suggest that exposure to nature may promote recovery from stress and fatigue. Indeed, our data on improvements of perceived greenery support this idea. Among adults, increases in perceived greenery were associated with a better mental health, i.e. less depressive symptoms. This is in line with earlier studies in which better mental health has been reported in greener neighborhoods (Beyer et al., 2014; De Vries et al., 2013; Richardson et al., 2013), and a recent study in the UK that showed that moving to a greener area was associated with improvements in mental health (Alcock et al., 2014). Moreover, the association between more greenery and less depressive symptoms in the current study seemed to be mediated by residents' perceptions of improved quality of green spaces and of mental restoration in green spaces. This is in line with theory (Kaplan and Kaplan, 1989; Ulrich et al., 1991), and might indicate that at least part of the association between greenery and mental health of adults can be explained by cognitive processing of environmental factors (Kremers et al., 2006). In addition, it indicates that green space is actually used for mental restoration, in line with previous research by Van den Berg et al. (2016). However, the overall picture of our results shows small effect sizes and many non-significant relationships, in line with the current evidence base regarding the minimal role of improvements in green in the environment, in influencing health and health behavior (e.g. De Vries et al., 2013; Hartig et al., 2014).

Based on ecological views of environmental influences on human behavior (Friedman and Wachs, 1999; Gubbels et al., 2014; Kremers et al., 2006), greenery can be expected to have differential effects on different people. Previous research has shown differences between subgroups regarding the importance of natural environments for physical activity (Hartig et al., 2014). In line with this, we found that changes in perceived greenery were associated with adults' but not adolescents' depressive symptoms. Moreover, we found several significant associations between greenery and outcomes in specific subgroups. Generally, higher educated and male adolescents, as well as native Dutch and older adults seemed to profit more from greenery in terms of physical activity. A recent qualitative study showed that nature can be a motivation to become active for older adults (Finlay et al., 2015). Interestingly, previous research has often reported teenagers and older adults as infrequent users of greenspaces for physical activity (Lee and Maheswaran, 2010). However, we showed positive associations between changes in greenery and physical activity were present in adolescents (leisure time cycling) and older adults (leisure time walking), but not younger adults. It is not clear why our findings with regard to age challenge previous findings. Our findings regarding the moderating role of gender in the relationship between greenery and physical activity are in line with recent research among children (Sanders et al., 2015b): boys seem to be more negatively affected by green spaces than girls.

\subsection{Strengths and limitations}

This is one of the few studies that investigated the impact of changes in greenery on physical activity and mental health in a very specific and understudied population: residents from severely deprived, low socio-economic neighborhoods. Much time and effort has been invested in the Urban40 study to recruit and retain this normally very hard to reach research population. As a result, the study provides a unique view on the relationship between greenery and health in very low SES populations. In 
addition, the study used both subjective and objective data. The combined use of subjective and objective measures of the environment has previously been recommended (Boehmer et al., 2007), as each method has its own problems (Hartig et al., 2014). Furthermore, we employed longitudinal data that allowed calculation of changes over time. In addition, this study included adolescents as well as adults. Furthermore, we included moderation and mediation analyses to examine subgroup effects and potential mediating pathways. Finally, we included multiple outcome variables: several types of physical activity, as well as mental health.

There are also some limitations concerning the study. First, we assessed the short term impact of changes in greenery. We might, therefore, have underestimated those effects that need more time to develop. Second, we used self-reported data on physical activity, irrespective of the site of the activity. Self-reported physical activity may have only low to moderate correspondence with objective measures (Cerin et al., 2016; Steene-Johannessen et al., 2016). However, as we were not only interested in PA as such, but also in the type of PA that might be affected by greenery, which cannot be assessed by accelerometry (see Kelly et al. (2016)), we feel self-report was a suitable measure of PA for the current study. Nonetheless, self-reported outcomes in general may have overestimated relations; especially with perceived environmental features. In addition, not taking site of the activity into account might have caused us to underestimate the impact of changes in green space within the neighborhood (Durand et al., 2011). However, for significant associations we examined mediating pathways that did include the site of the activity. Third, some of the measures used to assess changes in greenery might have been suboptimal. For instance, the NEWS uses a 4-point Likert scale, which might have insufficient sensitivity to measure change over time. Nonetheless, significant changes in perceived nature were observed for adolescents and adults (see Table 2), indicating sufficient sensitivity. Fourth, the green interventions in the intervention districts have been tailored to the local needs, resulting in a large variety of changes in green space. Our study does not allow for assessing the health impact of specific individual green interventions. Moreover, the greenery improvements were carried out simultaneously with many other interventions targeting problems with for example employment, housing or education. However, this may reflect the reality in which most green interventions take place, i.e. within the context of many other municipal interventions intended to improve the living situation. Nevertheless, it is possible, that the health impact of the improvements in green space might have been influenced by the impact of other interventions (Droomers et al., 2015). An alternative assumption could be that community effects on health are not the outcome of individual measures, but could only be produced by a combination of multiple complementary interventions. Adjustment for the number of other interventions that were part of the District Approach did not alter any of the results, however (results not shown). Fifth, although the study makes use of a longitudinal research design, the relatively small sample size is an additional limitation. Sixth, although we put much energy in trying to get a representative sample, the respondents in our study might not be fully representative for the population of inhabitants of deprived neighborhoods. The low response rates are considered as highly conservative figures, as many invitation letters did not reach the targeted respondents (e.g. letters were returned because respondents had moved, were not known on the address). These low response rates to the invitation might be interpreted as an indicator of selection bias. However, we have no reason to assume that the associations found in the current study, would be different in the non-responder group. Seventh and finally, although interviews and audits may have many advantages over the use of Geographical Information Systems, the basis for the objective changes in greenery was information given by the district managers. As noted by Droomers and colleagues (Droomers et al., 2014), not all activities might have been reported which may have led to an underestimation of intervention activities actually conducted. Moreover, the consequence of this approach was that objective measures were only available for 10 out of 20 districts, as interventions were only conducted in the districts from the Dutch District Approach.

\section{Conclusion}

Changes in the quantity or quality of greenery did not yield consistent positive results in terms of an increase in the prevalence of physical activity or good self-reported mental health among residents of severely deprived neighborhoods. It remains debatable whether presumed positive effects on public health are a valid argument to invest in green space. However, the present study does give some indications regarding positive effects of greenery on health and behavior in certain subgroups: increased greenery was associated with desirable effects on leisure time cycling by adolescents in general, leisure time walking by male adolescents and older adults, walking for active transport by highly educated adolescents and native Dutch adults, and depressive complaints of adults in general. More research into these and other moderating factors and the underlying mechanisms, such as mediation by cognitive processing, is necessary.

\section{Funding}

This paper is part of the URBAN40 study, which is financed by the Netherlands Organization for Health Research and Development (ZonMw) and the Dutch Ministry of the Interior and Kingdom Relations. The evaluation of the effect of intervening in green space in the context of the Dutch District Approach, reported in this paper, was financed by the Dutch Ministry of Economic Affairs (Grant number: 121010009).

\section{Competing interests}

The authors report no competing interests.

\section{References}

Alcock, I., White, M.P., Wheeler, B.W., Fleming, L.E., Depledge, M.H., 2014. Longitudinal effects on mental health of moving to greener and less green urban areas. Environ. Sci. Technol. 48 (2), 1247-1255.

Alfonzo, M.A., 2005. To walk or not to walk? The hierarchy of walking needs. Environ. Behav. 37, 808-836.

Beyer, K.M., Kaltenbach, A., Szabo, A., Bogar, S., Nieto, F.J., Malecki, K.M., 2014. Exposure to neighborhood green space and mental health: evidence from the survey of the health of Wisconsin. Int. J. Environ. Res. Public Health 11 (3), 3453-3472.

Boehmer, T.K., Hoehner, C.M., Deshpande, A.D., Brennan Ramirez, L.K., Brownson, R. C., 2007. Perceived and observed neighborhood indicators of obesity among urban adults. Int. J. Obes. 31 (6), 968-977.

Branas, C.C., Cheney, R.A., MacDonald, J.M., Tam, V.W., Jackson, T.D., Ten Have, T.R., 2011. A difference-in-difference analysis of health, safety, and greening vacant urban space. Am. J. Epidemiol. 174 (11), 1296-1306.

Campbell, N., Gaston, A., Gray, A., Rush, C., Maddison, R., Prapavessis, H., 2015. The Short Questionnaire to ASsess Health-enhancing (SQUASH) physical activity in adolescents: a validation using Doubly Labeled Water. J. Phys. Act. Health (Epub ahead of print).

Cerin, E., Cain, K.L., Oyeyemi, A.L., Owen, N., Conway, T.L., Cochrane, T., Van Dyck, D., et al., 2016. Correlates of agreement between accelerometry and self-reported physical activity. Med. Sci. Sport. Exerc. http://dx.doi.org/10.1249/ MSS.0000000000000870.

Cohen, D.A., Golinelli, D., Williamson, S., Sehgal, A., Marsh, T., McKenzie, T.L., 2009. Effects of park improvements on park use and physical activity: policy and 
programming implications. Am. J. Prev. Med. 37 (6), 475-480.

De Vries, S., van Dillen, S.M., Groenenwegen, P.P., Spreeuwenberg, P., 2013. Streetscape greenery and health: stress, social cohesion and physical activity as mediators. Soc. Sci. Med. 94, 26-33.

Droomers, M., Harting, J., Jongeneel-Grimen, B., Rutten, L., van Kats, J., Stronks, K., 2014. Area-based interventions to ameliorate deprived Dutch neighborhoods in practice: does the Dutch District Approach address the social determinants of health to such an extent that future health impacts may be expected? Prev. Med. 61, 122-127.

Droomers, M., Jongeneel-Grimen, B., Kramer, D., De Vries, S., Kremers, S., Bruggink, J.W., Stronks, K., 2015. The impact of intervening in green space in Dutch deprived neighborhoods on physical activity and general health: results from the quasi-experimental URBAN40 study. J. Epidemiol. Commun. Health. http://dx. doi.org/10.1136/jech-2014-205210 (Epub ahead of print).

Dumith, S.C., Gigante, D.P., Domingues, M.R., Kohl 3rd, H.W., 2011. Physical activity change during adolescence: a systematic review and a pooled analysis. Int. J. Epidemiol. 40, 685-698.

Durand, C.P., Andalib, M., Dunton, G.F., Wolch, J., Pentz, M.A., 2011. A systematic review of built environment factors related to physical activity and obesity risk: implications for smart growth urban planning Obes. Rev, 12 (5) e173-e182.

Ferdinand, A.O., Sen, B., Rahurkar, S., Engler, S., Menachemi, N., 2012. The relationship between built environment and physical activity: a systematic review. Am. J. Public Health 102 (10), e7-e13.

Finlay, J., Franke, T., McKay, H., Sims-Gould, J., 2015. Therapeutic landscapes and wellbeing in later life: Impacts of blue and green spaces for older adults. Health Place 34, 97-106.

Fitzhugh, E.C., Bassett Jr., D.R., Evans, M.F., 2010. Urban trails and physical activity: a natural experiment. Am. J. Prev. MEd 39 (3), 259-262.

Friedman, S.L., Wachs, T.D., 1999. Measuring Environment Across the Life Span. Emerging Methods and Concepts. American Psychological Association, Washington.

Gubbels, J.S., Van Kann, D.H., de Vries, N.K., Thijs, C., Kremers, S.P., 2014. The next step in health behavior research: the need for ecological moderation analyses an application to diet and physical activity at childcare. Int. J. Behav. Nutr. Phys. Act. 11, 52.

Hartig, T., Mitchell, R., De Vries, S., Frumkin, H., 2014. Nature and health. Annu. Rev. Public Health 35, 207-228.

Hillsdon, M., Coombes, E., Griew, P., Jones, A., 2015. An assessment of the relevance of the home neighbourhood for understanding environmental influences on physical activity: how far from home do people roam? Int. J. Behav. Nutr. Phys. Act. 12, 100.

Hunter, R.F., Christian, H., Veitch, J., Astell-Burt, T., Hipp, J.A., Schipperijn, J., 2015. The impact of interventions to promote physical activity in urban green space: a systematic review and recommentdations for future research. Soc. Sci. Med. 124, 246-256.

Kalpan, R., Kalpan, S., 1989. The Experience of Nature. A Psychological Perspective. Press Syndicate of the University of Cambridge, Cambridge, USA.

Kelly, P., Fitzsimons, C., Baker, G., 2016. Should we reframe how we think about physical activity and sedentary behavior measurement? Validity and reliability reconsidered. Int. J. Behav. Nutr. Phys. Act 13, 32.

Koohsari, M.J., Mavoa, S., Villanueva, K., Sugiyama, T., Badland, H., Kaczynski, A.T., Owen, N., Giles-Corti, B., 2015. Public open space, physical activity, urban design and public health: Concepts, methods and research agenda. Health Place 33, 75-82.

Kremers, S.P., de Bruijn, G.J., Visscher, T.L., van Mechelen, W., de Vries, N.K., Brug, J., 2006. Environmental influences on energy balance-related behaviors: a dualprocess view. Int. J. Behav. Nutr. Phys. Act. 3, 9.

Kweon, B.S., Ellis, C.D., Lee, S.W., Al, E., 2006. Large-scale environmental knowledge: investigating the relationship between self-reported and objectively-measured physical environments. Environ. Behav. 38, 72-91.

Lachowycz, K., Jones, A.P., 2011. Greenspace and obesity: a systematic review of the evidence. Obes. Rev. 12 (5), e183-e189.

Lee, A.C.K., Maheswaran, R., 2010. The health benefits of urban green spaces: a review of the evidence. J. Public Health 33, 212-222.

Leslie, E., Sugiyama, T., Ierodiaconou, D., Kremer, P., 2010. Perceived and objectively measured greeness of neighbourhoods: are they measuring the same thing? Landsc. Urban Plan. 95, 28-33.

MacKinnon, D.P., Fairchild, A.J., Fritz, M.S., 2007. Mediation analysis. Annu. Rev. Psychol. 58, 593.

Mytton, O.T., Townsend, N., Rutter, H., Foster, C., 2012. Green space and physical activity: an observational study using Health Survey for England data. Health Place 18 (5), 1034-1041.

Radloff, L.S., 1977. The CES-D scale: a self-report depression scale for research in the general populations. Appl. Psychol. Meas. 1, 385-401.

Richardson, E.A., Pearce, J., Mitchell, R., Kingham, S., 2013. Role of physical activity in the relationship between urban green space and health. Public Health 127 (4), 318-324.

Saelens, B.E., Sallis, J.F., Black, J.B., Chen, D., 2003. Neighborhood-based differences in physical activity: an environmental scale evaluation. Am. J. Public Health 93 (9), 1552-1558.

Sallis, J.F., Cerin, E., Conway, T.L., Adams, M.A., Frank, L.D., Pratt, M., Salvo, D., et al., 2016. Physical activity in relation to urban environments in 14 cities worldwide: a cross-sectional study. Lancet. http://dx.doi.org/10.1016/S0140-6736(15) 01284-2.

Sallis, J.F., Cervero, R.B., Ascher, W., Henderson, K.A., Kraft, M.K., Kerr, J., 2006. An ecological approach to creating active living communities. Annu. Rev. Public Health 27, 297-322.

Sanders, T., Feng, X., Fahey, P.P., Lonsdale, C., Astell-Burt, T., 2015a. Greener neighbourhoods, slimmer children? Evidence from 4423 participants aged 6 to 13 years in the Longitudinal Study of Australian children. Int. J. Obes. (Epub ahead of print)

Sanders, T., Feng, X., Fahey, P.P., Lonsdale, C., Astell-Burt, T., 2015b. The influence of neighborhood green space on children's physical activity and screen time: findings from the longitudinal study of Australian children. Int. J. Behav. Nutr Phys. Act. 12, 126.

Steene-Johannessen, J., Anderssen, S.A., Van der Ploeg, H.P., Hendriksen, I.J.M., Donnelly, A.E., Brage, S., Ekelund, U., 2016. Are self-report measures able to define individuals as physically active or inactive? Med. Sci. Sport. Exerc. http: //dx.doi.org/10.1249/MSS.0000000000000760.

Tester, J., Baker, R., 2009. Making the playfields even: evaluating the impact of an environmental intervention on park use and physical activity. Prev. Med. 48 (4) 316-320.

Tilt, J.H., Unfried, T.M., Roca, B., 2007. Using objective and subjective measures of neighborhood greenness and accessible destinations for understanding walking trips and BMI in Seattle, Washington. Am. J. Health Promot 21 (4 Suppl), 371-379.

Ulrich, R.S., Simons, Robert F., Losito, Barbara D., Fiorito, E., Miles, M.A., Zelson, M. 1991. Stress recovery during exposure to natural and urban environments. J. Environ. Psychol. 11 (3), 201-230.

UNESCO (United Nations Educational, Scientific and Cultural Organization), 2011. International Standard Classification of Education. ISCED 2011. UNESCO Insitute For Statistics, Montreal, Canada.

Van Cauwenberg, J., de Bourdeaudhuij, I., de Meester, F., Van Dyck, D., Salmon, J., Clarys, P., Deforche, B., 2011. Relationship between the physical environment and physical activity in older adults: a systematic review. Health Place 17 (2), 458-469.

Van den Berg, M., Van Poppel, M., Van Kamp, I., Andrusaityte, S., Balseviciene, B., Cirach, M. Danileviciute, A., et al., 2016. Visiting green space is associated with mental health and vitality: A cross-sectional study in four European cities. Health Place 38, 8-15.

Van Kann, D.H.H., Kremers, S.P.J., Gubbels, J.S., Bartelink, N.H.M., De Vries, S.I., De Vries, N.K., Jansen, J., 2014. The association between the physical environment of primary schools and active school transport. Environ. Behav. 2014, 1-18.

Wendel-Vos, G.C.W., Schuit, A.J., Saris, W.H.M., Kromhout, D., 2003. Reproducibility and relative validity of the short questionnaire to assess health-enhancing physical activity. J. Clin. Epidemiol. 56 (12), 1163-1169. 